\title{
A Study on Teenage Pregnancy and its Maternal and Fetal Outcome
}

\author{
Dr. Rupakala B $\mathbf{M}^{1}$, Dr. Shruthi A G $\mathbf{G}^{2}$, Dr. Nagarathnamma $\mathbf{R}^{3}$ \\ ${ }^{1}$ Professor, Department of Obstetrics \& Gynecology, Rajarajeshwari Medical College and Hospital, Karnataka, India \\ ${ }^{2}$ MS, Resident, Department of Obstetrics \& Gynecology, Rajarajeshwari Medical College College and Hospital, Karnataka, India \\ ${ }^{3}$ Professor \& Head of Department of Obstetrics \& Gynecology, Rajarajeshwari Medical College College and Hospital, Karnataka, India
}

\begin{abstract}
Background: Teenage pregnancy rates varies vastly between different countries and different regions within a country. Such pregnancies are seen mostly amongst the poorer and less educated sections of the society. In developed countries majority of teenage pregnancies occur to unmarried girls unlike developing countries including India where teenage pregnancies occur to married girls and are associated with early marriages. Aim \& Objectives: To find out the incidence and to evaluate the effect of pregnancy in teenage girls and its maternal and fetal outcome. Material \& Methods: It is a one year hospital based clinical prospective study of all teenage pregnant females admitted to a tertiary care centre. Required details were collected on a proforma by taking history and following up the patients from admission to delivery. MS Excel was used for statistical purpose. Results: Teenage pregnancy 9.76\% of the total Obstetric admissions. In this study $52.08 \%$ teenage pregnancies were associated with complications. The major maternal complications were Preterm labour7.3\%, Hypertensive Disorders of Pregnancy 6.25\%, Premature Rupture of Membranes 7.3\%, anemia (3.1\%). Low Birth Weight $19.7 \%$ and stillbirths $1 \%$ were major adverse fetal outcomes. Conclusion: Teenage pregnancy is still a common occurrence. It has adverse impact on the health of teenage mothers leading to various adverse maternal and fetal outcome.
\end{abstract}

Keywords: Teenage pregnancy, Clinical prospective study, maternal outcome, fetal outcome and high risk pregnancy

\section{Introduction}

World Health Organization defines Teenage Pregnancy as "any pregnancy from a girl who is 1019 years of age", the age being defined as her age at the time the baby is born. Often the terms "Teenage pregnancy" and "Adolescent pregnancy" are used as synonyms.

Teenage pregnancy is coming up as one of the most important social and public health problems all over the world with varying prevalence rates.

About 16 million women 15-19 years old give birth each year, about $11 \%$ of all births worldwide. Ninety-five per cent of these births occur in low- and middle-income countries.Although adolescents aged 10-19 years account for $11 \%$ of all births worldwide, they account for $23 \%$ of the overall burden of disease. Due to pregnancy and childbirth. Fourteen percent of all unsafe abortions in low- and middleincome countries are among women aged 15-19 years.

Stillbirths and death in the first week of life are $50 \%$ higher among babies born to mothers younger than 20 years than among babies born to mothers 20-29 years old.The rates of preterm birth, low birth weight and asphyxia are higher among the children of adolescents, all of which increase the chance of death and of future health problems for the baby.

Although adolescent marriage is cognizable offence in India, it is still a common practice in many parts of the country. A high fertility rate, social customs, poverty and ignorance make early marriage a common feature in this part of the world. So this teenage group is most vulnerable and maximum attention should be diverted to them.
With modernization, teenage pregnancy rate is rapidly declining in developed countries, but it is still high in developing countries like India. The scenario of teenage pregnancy in developed countries is quite different from that of the developing countries and have distinctly different rates of pregnancy as well.

In India, teenage pregnancy constitutes $8-14 \%$ of total pregnancies. Complications of pregnancy and childbirth in women between 15-19 years of age are the leading cause of mortality among women in India. Hence teenage pregnancy is a serious problem today all over the world and more so in developing countries like India.

Objectives of this study is to find out the incidence and to evaluate the effect of pregnancy in teenage girls (13-19 years) and its maternal and fetal outcome.

\section{Materials and Methods}

This is a one year clinical prospective study carried out in the Department of Obstetrics and Gynecology, at a tertiary care Centre of Karnataka, India. All pregnant females admitted to the Hospital in the age group of 13-19 years during the study period were included and all pregnant females equal to or more than 20 years admittedto the Hospital during the same period were excluded from the study. The required details were collected by history taking and following up the patients from admission to delivery. Data was compiled in MS Excel sheet. Frequencies and percentages were computed for the results. 


\section{International Journal of Science and Research (IJSR) \\ ISSN (Online): 2319-7064}

Index Copernicus Value (2013): 6.14 | Impact Factor (2015): 6.391

\section{Result and Observation}

In the present study there were 192 teenage mothers admitted during the study period amongst the total obstetric admissions of 1967, giving an incidence of $9.76 \%$ of teenage pregnancy (Figure 1).

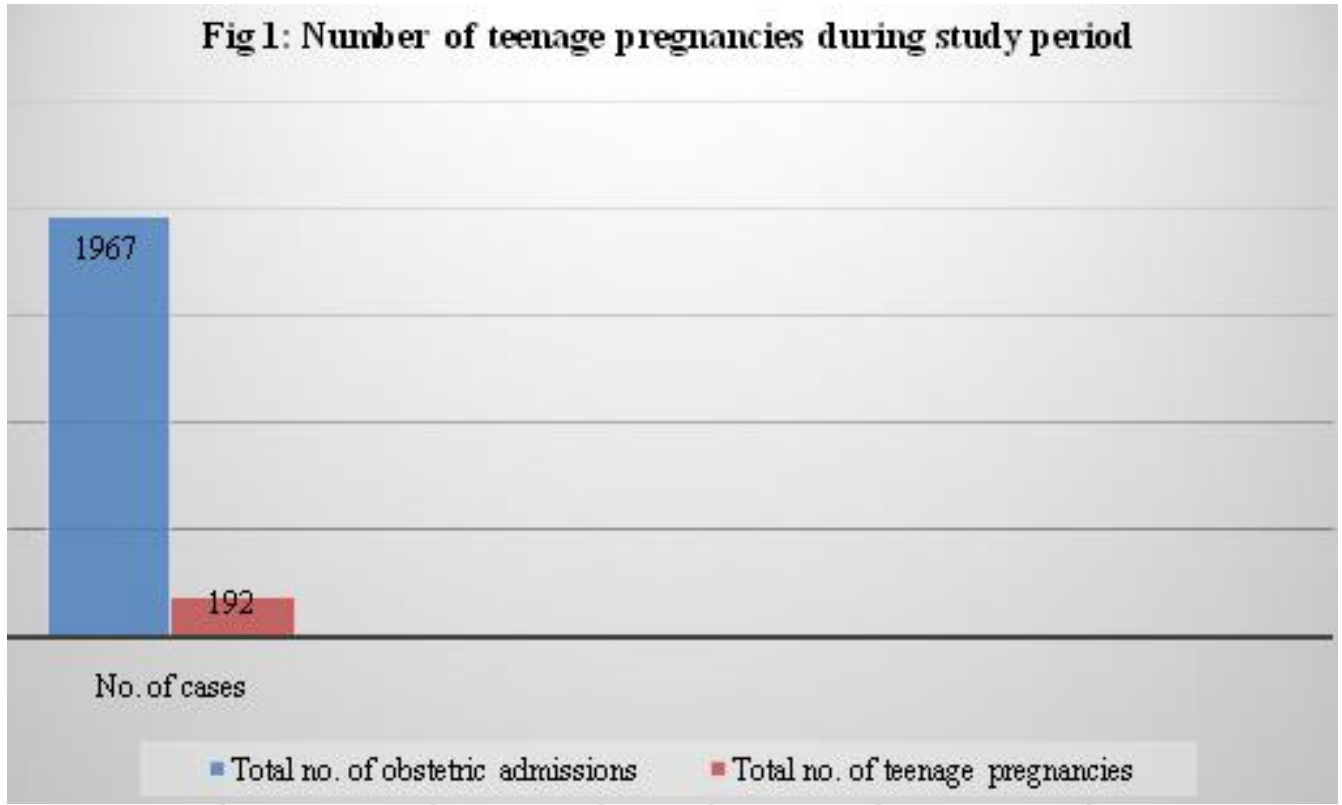

Out of the 192 teenage pregnancies, 100 ( 52.08\%) were associated with complications and the remaining 92 (47.91\%) were without any complication. Out of 192 teenage pregnancies which were associated with complications, $78(78 \%)$ were associated with single complication, whereas $22(22 \%)$ were associated with multiple complications, indicating that teenage pregnancies are high risk pregnancies (Table 1).

Table 1: Distribution according to presence of complication

\begin{tabular}{|c|c|c|}
\hline Complications & No. of pregnancies & percentage \\
\hline With complication & 100 & $52.08 \%$ \\
\hline Without complication & 92 & $47.91 \%$ \\
\hline Total & 192 & $100 \%$ \\
\hline
\end{tabular}

The most common complication associated with teenage pregnancy was Preterm Labour (14). Amongst 12 mothers who had Hypertensive Disorders, 8 had Preeclampsia and 4 had Gestational Hypertension. 14 of them had premature rupture of membranes, 7 of them had hypothyroidism and 6 pregnant teenagers were found to be anaemic(Table No.2).

Table 2: Complications in teenage pregnancy

\begin{tabular}{|c|c|c|}
\hline Complication & No. of cases & Percentage \\
\hline Malpresentation & 16 & $8.3 \%$ \\
\hline PROM & 14 & $7.3 \%$ \\
\hline Preterm labour & 14 & $7.3 \%$ \\
\hline Medical disorders & 13 & $6.8 \%$ \\
\hline Hypertensive disorders & 12 & $6.25 \%$ \\
\hline IUGR & 10 & $5.2 \%$ \\
\hline CPD & 9 & $4.7 \%$ \\
\hline Oligohydramnios & 6 & $3.1 \%$ \\
\hline Multiple pregnancies & 2 & $1 \%$ \\
\hline IUFD & 2 & $1 \%$ \\
\hline
\end{tabular}

Out of the 192 teenage mothers who delivered, majority i.e $135(70.3 \%)$ had normal vaginal delivery and $57(29.7 \%)$ had cesarean section.

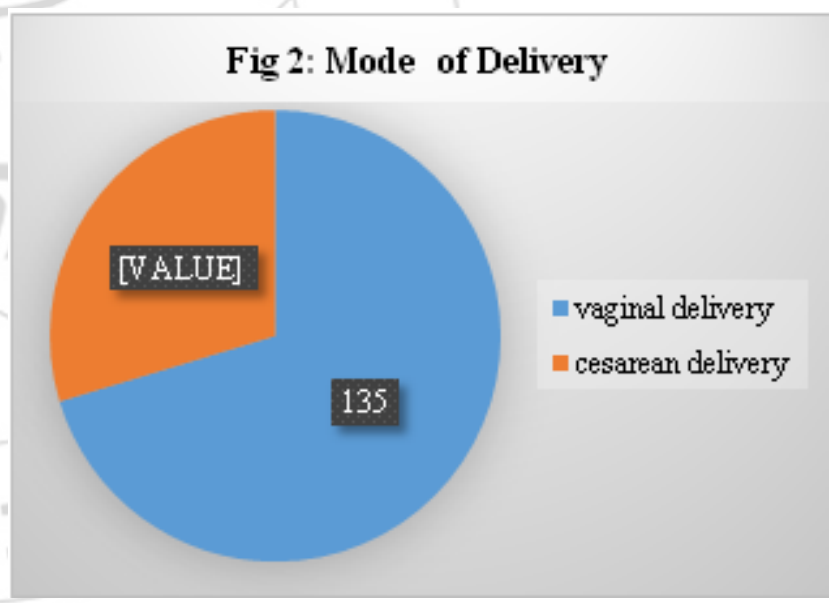

Out of the 57 teenage mothers delivered by Cesarean Section, 22 mothers had more than one indication for Cesarean Section. Majority of Cesarean Section were due to Fetal Distress. It was followed by Malpresentation (16) of which 14 was for Breech presentation and one each for face and brow presentation. The other indications for $\mathrm{C}$ - Section in teenage mothers were oligohydramnios, severe preeclampsia, CPD and Obstructed Labour (TableNo. 3).

Table 3: Indication for Cesarean Section

\begin{tabular}{|c|c|c|}
\hline Indication & Number & Percentage \\
\hline Fetal distress & 22 & $38.5 \%$ \\
\hline Malpresentation & 16 & $28 \%$ \\
\hline Oligohydramnios & 6 & $10.5 \%$ \\
\hline Severe preeclampsia & 5 & $8.8 \%$ \\
\hline CPD & 5 & $8.8 \%$ \\
\hline Obstructed labour & 4 & $7 \%$ \\
\hline
\end{tabular}




\section{International Journal of Science and Research (IJSR) \\ ISSN (Online): 2319-7064}

Index Copernicus Value (2013): 6.14 | Impact Factor (2015): 6.391

Majority of the babies (136) born out of such pregnancies were healthy babies. The most common adverse fetal outcome noted in the study was Low Birth Weight babies (38 babies). Amongst 16 babies who needed NICU admissions, 10 were Low Birth Weight babies. There were 2 Still born babies.

Table 4: Fetal outcome of teenage pregnancy

\begin{tabular}{|l|l|l|}
\hline \multicolumn{1}{|c|}{ Fetal outcome } & Number & Percentage \\
\hline Active and healthy & 136 & $70.8 \%$ \\
\hline Low birth weight & 38 & $19.7 \%$ \\
\hline NICU admissions & 16 & $8.3 \%$ \\
\hline Still birth & 2 & $1.04 \%$ \\
\hline
\end{tabular}

\section{Discussion}

In the present study, $9.76 \%$ of the study population were teenage pregnancies which corelated with incidences of other studies, GazalaYasminet al, Ambadekar NNet al, Dubashi SS et al $(3,16,17)$.

Incidence of C-Section in the present study was $29.7 \%$. The number of vaginal deliveries were more in the teenage group probably because of the smaller size of the babies. Similar results were found in other studiesTrivedi $S$ S et al, Mukhopadhyay et al,Mahavarkar S. H et al and Sagili Het al $[5,6,7,8]$. However two studies have shown higher rate of caesarian sections. This may be due to a difference in the setting,Nwobodo et al andJimoh et al [9.10]. Cases of obstructed labour are higher in the teenage group and may be due to weaker physical strength of the teenage mothers.

The incidence of Preeclampsia was $6.25 \%$. Although anemia, and preeclampsia were higher in the cases, the difference was not statistically significant. Similar results were found in Mahavarkar S. H et al [7]. A higher study population is needed to conclude this finding.

As pregnant teenagers often receive inadequate antenatal care, their anemia during labour and the postpartum period usually get worse. In developing countries more than $25 \%$ of teenage mothers were found to be anemic as revealed in studies conducted by Saxena et al,(11)Bhalerao et al(12) And Rahman MM et al.(13) In contrast to it our study found a lower incidence $(3.125 \%)$.

Consistent with previous studies, cases of preterm, LBW and foetal distress were higher in teenagegroup. But unlike other studies, the difference was not statistically significant $[14,5,6,7,15]$.

\section{Conclusion}

The present study concludes that Preterm labour, Hypertensive Disorders of Pregnancy, Premature Rupture of Membrane, anemia, malpresentations, IUGR, IUFD were major maternal complications; Low Birth Weight and NICU admissionswere major adverse fetal outcomes. Teenage pregnancy today, still represent one of the most important public health problems. There is no doubt that the obstetrical problems can be managed by modern medicine and so the risk of Teenage pregnancy can be diminished.
The health care provider should consider Teenage pregnancy as a 'high risk' pregnancy and should educate the pregnant teenagers to have more number of antenatal visits so that the signs and symptoms of various complications of teenage pregnancy could be recognized at the earliest. Attention should be given to the use of various screening and diagnostic tests and to the interventions needed if any complication does occur during the course of pregnancyor labour. Proper monitoring of the progress of labour is important to prevent prolonged labour. Education of the female child can play a significant role in delaying marriage and hence delaying childbearing, thus protecting the young girl from being exposed to the various complications of teenage pregnancy. There is a need to promote the use of Contraceptives amongst the married teenagers and ensuring the availability of contraceptives at a wider scale. Access to contraceptives is the cornerstone in preventing teenage pregnancies while access to abortion services is crucial for managing them. Good antenatal and intranatal services, good neonatal services, contraceptive services and abortion services, all together can minimize the various risks associated with teenage pregnancies to a large extent. With all these measures, we can hope for a world-wide decline in the trend of teenage pregnancy rates and complications in the years to come.

\section{References}

[1] World Health Organization, United Nations Population Fund: Married adolescents: no place of safety. Geneva: WHO-UNFPA; 2006.

[2] Adolescent pregnancy- Issues in adolescent health and development, WHO discussion papers on adolescence. WHO, 2004 Pg 86.

[3] Gazala Yasmin, Aruna Kumar, Bharti Parihar. "Teenage Pregnancy - Its Impact On Maternal And Fetal Outcome". International Journal of Scientific Study. 20141(6):9-13.

[4] SnigdhaKamini, Dr. Krishna VeniAvvaru. Teenage Pregnancy: Maternal and Fetal Outcomes. IOSR Journal of Dental and Medical Sciences.2014(4): 41-44.

[5] Trivedi S S., and ShikhaPasrija.Teenage pregnancies and their obstetric outcomes, Tropical doctor,37(2),2007,85-88.

[6] Mukhopadhyay, Prianka, R. N. Chaudhuri, and Bhaskar $\mathrm{P}$, Hospital-based perinatal outcomes and complications in teenage pregnancy in India, Journal of health, population, and nutrition,28(5), 2010, 494.

[7] Mahavarkar S. H, C. K. Madhu, and V. D. Mule., A comparative study of teenage pregnancy, Journal of Obstetrics \&Gynecology,28(6), 2008,604-607.

[8] Sagili H, N Pramya, Karthiga P, Mariano M, and P. ReddiRani.,Are teenage pregnancies at high risk? A comparison study in a developing country, Archives of gynecology and obstetrics,285(3), 2012, 573-577.

[9] Nwobodo, Emmanuel I., and Kasimu U. Adoke, Obstetric Outcome of teenage pregnancies at a tertiary care hospital in Sokoto, Nigeria, Tropical Journal of Obstetrics and Gynaecology,22(2), 2006 ,168-170.

[10] Jimoh, Adiodun S., and Ishaq-F. Abdul,Outcome of teenage pregnancies in Ilorin, Nigeria, Tropical Journal of Obstetrics and Gynaecology, 21(1), 2005,27-31. 


\section{International Journal of Science and Research (IJSR) \\ ISSN (Online): 2319-7064}

Index Copernicus Value (2013): 6.14 | Impact Factor (2015): 6.391

[11] Saxena P, Salhan S, Chatopadhyay B,Kohli MPS, Nandan D and AdhishSV. Obstetrics and perinatal outcome of teenage and older primigravidas - A retrospective analysis. Health and Population: Perspectives and Issues. 2001; 33(1):16-22.

[12] Bhalerao AR, Desai SV, Dastur NA,Daftary SN. Outcome of teenage pregnancy. J Postgrad Med.1990;36:136-9.

[13] Rahman MM, Hasan M, Akhter S, Sultan P. Adolescent pregnancy complication and wastage in Bangladesh. J. Nepal Paediatr. 2010; 30(3):147-153.

[14] Kumar A., Singh T, Basu S, Pandey S, \& Bhargava $\mathrm{V}$,Outcome of teenage pregnancy. The Indian Journal of Pediatrics,74(10),2007, 927-931.

[15] Yadav, Siddhartha, Dilip C, K. C. Narayan, Rajesh K $\mathrm{M}$, Achyut $\mathrm{S}$ et al,Adversereproductive outcomes associated with teenage pregnancy." McGill Journal of Medicine: MJM,11(2),2008, 141.

[16] Ambadekar NN, Khandait DW, Zodpey SP, Kasturwar NB, Vasudeo ND. Teenage pregnancy outcome: A record based study. Indian J Med Sci. 1999;53:14-7.

[17] Dubashi SS, Wani R. Teenage pregnancy. Bombay Hospital journal. 2008;50(2): 236-239. 